\title{
Article \\ Recombination of Poly(Acrylic Acid) Radicals in Acidic Aqueous Solutions: A Pulse Radiolysis Study
}

\author{
Małgorzata Matusiak, Sławomir Kadłubowski and Piotr Ulański *(D) \\ Institute of Applied Radiation Chemistry, Faculty of Chemistry, Lodz University of Technology, \\ Wróblewskiego 15, 93-590 Lodz, Poland; malgorzata.matusiak.1@p.lodz.pl (M.M.); \\ slawomir.kadlubowski@p.lodz.pl (S.K.) \\ * Correspondence: piotr.ulanski@p.lodz.pl; Tel.: +48-42-631-3184
}

Citation: Matusiak, M.;

Kadłubowski, S.; Ulański, P.

Recombination of Poly(Acrylic Acid) Radicals in Acidic Aqueous Solutions: A Pulse Radiolysis Study. Appl. Sci. 2021, 11, 10142. https://doi.org/ 10.3390/app112110142

Academic Editor: Luca Fiori

Received: 30 September 2021

Accepted: 27 October 2021

Published: 29 October 2021

Publisher's Note: MDPI stays neutral with regard to jurisdictional claims in published maps and institutional affiliations.

Copyright: (c) 2021 by the authors. Licensee MDPI, Basel, Switzerland. This article is an open access article distributed under the terms and conditions of the Creative Commons Attribution (CC BY) license (https:// creativecommons.org/licenses/by/ $4.0 /)$.
Abstract: Carbon-centered radicals have been randomly generated on the chains of poly(acrylic acid), PAA, the simplest synthetic anionic polyelectrolyte, by pulse-irradiating its dilute, oxygen-free aqueous solutions by $6 \mathrm{MeV}$ electron beam. In some experiments, oligo(acrylic acid), OAA, and propionic acid, PA, were used as PAA models. Recombination kinetics of PAA radicals has been followed by fast spectrophotometry. A strong $\mathrm{pH}$ dependence of radical lifetime on $\mathrm{pH}$, and thus on the linear charge density due to deprotonated carboxylate groups, has been confirmed, while a weaker amplitude of $\mathrm{pH}$ dependence was observed for OAA and PA. Decay kinetics of PAA radicals in the protonated state, at $\mathrm{pH}$ 2, have been studied in some detail. At moderate doses of ionizing radiation, resulting in a moderate average initial number of radicals per chain, $Z_{R 0}$, the decay can be satisfactorily described by a second-order kinetic model, but a somewhat better fit is obtained by using a dispersive kinetics approach. While for a constant polymer concentration the reciprocal half-lives are proportional to the initial radical concentrations, such a data series for different PAA concentrations do not overlap, indicating that the overall radical concentration is not the decisive factor controlling the kinetics. Arranging all data, in the form of second-order rate constants, as a function of the average initial number of radicals per chain allows one to obtain a common dependence. The latter seems to consist of two parts: a horizontal one at low $Z_{R 0}$ and another one of positive slope at higher $Z_{R 0}$. This is interpreted as two kinetic regimes where two distinct reactions dominate, intermolecular and intramolecular recombination, respectively. Comparison of the low $Z_{R 0}$ data with calculations based on the translational diffusion model indicate that the latter is not the rate-controlling process in intermolecular recombination of polymer radicals; segmental diffusion is the more likely candidate.

Keywords: reaction kinetics; free radicals; radiation chemistry; pulse radiolysis; polyelectrolytes; poly(acrylic acid); propionic acid; intramolecular recombination; intermolecular reaction

\section{Introduction}

Changes in public awareness and the related drive to move from an economy based on fossil resources to the new one, based on renewable materials, are also reflected in the field of polymers and plastics. While much activity is focused on replacing commodity synthetic polymers by their green-sourced and biodegradable equivalents, this does not mean that synthetic polymers have no place in the future economy. Specialty polymers, used in new organic electronics and photovoltaics, biomaterials, drug delivery systems, etc., will definitely make use of the extraordinary properties that synthetic polymers can provide. These applications require the possibilities of synthesizing polymers of precisely known and well-controlled architecture, such as can be provided by modern synthetic methods based, for instance, on controlled radical polymerization [1-5]. To achieve full control over the processes involved in the synthesis of these specialty polymers and products, it is desirable to know the detailed kinetics and mechanisms of the involved elementary 
chemical reactions. In free-radical polymerization, our knowledge on propagation kinetics has been greatly increased in the last two decades due to a new experimental approach: PLPSEC (Pulsed Laser Polymerization-Gel Permeation Chromatography) [6-9]. Much attention has also been devoted to the termination reaction, i.e., recombination of two terminal radicals on the growing polymer chains, but it seems that the picture is not yet complete, especially when it comes to termination rate constant dependence on molecular weight and polymer concentration, and also to pinpointing the rate-determining process [10-14].

The importance of polymer radical recombination is not limited to polymerization. Polymer crosslinking processes in which radicals generated randomly on macromolecules come into proximity and recombine to form a covalent bond are also of high importance if we take into account the broad variety of products based on crosslinked polymers. If we limit the scope of our discussion to hydrophilic polymers being crosslinked in aqueous solution, kinetic features of the radical recombination process control the final outcome and character of the products, being either macroscopic (wall-to-wall) hydrogels or nanogels $[15,16]$. The former are formed when intermolecular recombination prevails, and the latter are products of predominantly intramolecular crosslinking, i.e., recombination taking place between the radicals initially located on the same polymer chain. While macroscopic hydrogels have been known and used, mainly in medicine, since the 1960s [17-26], nanogels are relatively new materials; interest in their synthesis and applications has risen rapidly in parallel with the developments in nanomedicine, controlled drug delivery, gene therapy, and targeted radiopharmaceuticals [27-38]. While there are many methods to synthesize nanogels, those allowing controlled direct generation of many free radicals on macromolecules in solution seem to be very attractive. Pulses of ionizing radiation applied to aqueous polymer solutions are used to generate, in an instant, a known average number of radicals on each chain in a system that is free of any additives (initiators, monomers, crosslinking agents, surfactants), making this procedure particularly suitable to obtain nanogels for medical applications [15,28,39-44]. In this work we use this approach to generate free radicals on polymer chains and study the kinetics of their recombination. Our aim is to learn about the kinetic features of these reactions, including its classical or non-classical character, to see how kinetics are influenced by various parameters, to learn how we can kinetically differentiate the intra- and intermolecular recombination, as well as to provide some hints as to the nature of the rate-determining step of intermolecular recombination of polymer radicals.

Our model compound is poly(acrylic acid), PAA, the simplest synthetic ionic polyelectrolyte, being widely used in industry and medicine (Figure 1) [45,46].

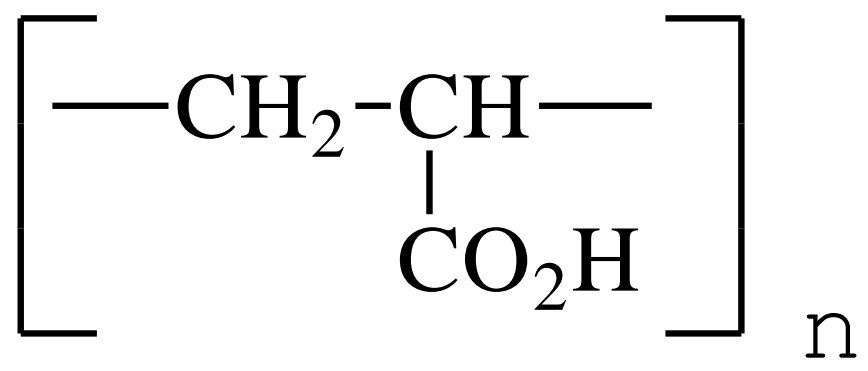

Figure 1. Monomer unit of poly(acrylic acid), PAA.

PAA is well soluble in water, easy to handle, and available at various molecular weights. Macroscopic PAA hydrogels are stimuli-sensitive, which makes them attractive as chemical sensors, actuators, etc. [47-49]. Since we intend to generate PAA radicals by ionizing radiation, we take advantage of the fact that radiation chemistry of PAA has been previously studied in some detail [15,50-54]. Moreover, our interest in this polymer is stimulated by recent progress in synthesizing, by the radiation technique, and studying both physicochemical and application-oriented properties of nanogels based either on 
copolymers or homopolymers of acrylic acid [15,38,55-63]. In this study we focus on protonated PAA since this is the form that allows to obtain nanogels upon irradiation, and also because the kinetic results obtained for the non-ionized form are of broader relevance for free radical reactions in non-ionic polymers.

\section{Materials and Methods}

\subsection{Materials}

The substrates were poly(acrylic acid) (PAA) of nominal weight-average molecular weight $M_{w}=450 \mathrm{kDa}$, oligo(acrylic acid) (OAA) of nominal $M_{w}=1.8 \mathrm{kDa}$ (both from SigmaAldrich, Darmstadt, Germany), and propionic acid (ACS reagent, $\geq 99.5 \%$, Sigma-Aldrich, Darmstadt, Germany) used as a low-molecular-weight model compound. Solutions were prepared in water purified by TKA-Micropure system (conductivity $0.05 \mu \mathrm{S} \mathrm{cm}-1,0.2 \mu \mathrm{m}$ filter, Thermo Fisher Scientific, Waltham, MA, USA). Perchloric acid $\left(\mathrm{HClO}_{4}, 70 \%\right.$, SigmaAldrich, Darmstadt, Germany) and sodium hydroxide (NaOH, pure PA, POCH SA, Gliwice, Poland) were used for $\mathrm{pH}$ adjustment. Before irradiation, the solutions were saturated with argon (5.0, Ar $\geq 99.999 \%$, Linde Gaz Polska, Łódź, Poland) or nitrous oxide $\left(\mathrm{N}_{2} \mathrm{O}\right.$, medical grade, Linde Gaz Polska, Łódź, Poland). Nitrous oxide has been purified from traces of oxygen by passing through an alkaline solution of pyrogallol (pure p.a., Chempur, Piekary Śląskie, Poland). $\mathrm{N}_{2} \mathrm{O}$-saturated aqueous solutions containing $10 \mathrm{mmol} \mathrm{dm}^{-3}$ potassium thiocyanate (KSCN, ACS for analysis, Supelco, Darmstadt, Germany) were used to determine the dose of ionizing radiation delivered to the solution sample by single electron pulse.

\subsection{PAA Solutions Preparation}

Before preparation of the PAA solutions, the polymer was dried overnight in a vacuum dryer at $50{ }^{\circ} \mathrm{C}$ to remove traces of solvent, water, and monomer. Dilute aqueous solutions of linear PAA at a monomer unit concentration of $2.5-50 \mathrm{mmol} \mathrm{dm}^{-3}$ were prepared by overnight stirring at $60{ }^{\circ} \mathrm{C}$. For experiments performed in acidic solutions, perchloric acid was used to adjust $\mathrm{pH}$, due to the relatively high resistance of perchlorate to ionizing radiation [64].

Care was taken to avoid contamination with metal ions. Before use, all the glassware was soaked overnight in $1 \mathrm{mmol} \mathrm{dm}^{-3}$ ethylenediaminetetraacetic acid (EDTA, SigmaAldrich, Darmstadt, Germany) solution at $60{ }^{\circ} \mathrm{C}$ and then rinsed with purified water. It has been shown that trace amounts of transition metal ions, in particular iron, can interfere with the reactions of PAA radicals, especially in neutral and alkaline solutions $[50,65]$.

\subsection{PAA Solution Characterization}

\subsubsection{Dynamic Light-Scattering Measurements (DLS)}

The diffusion coefficient $(D)$ and hydrodynamic radius $\left(R_{h}\right)$ of linear non-irradiated PAA were determined by dynamic laser light-scattering measurements using ZetaSizer Nano ZS (Malvern Instruments Ltd., Malvern, Worcestershire, United Kingdom) at a temperature of $25.0 \pm 0.1{ }^{\circ} \mathrm{C}$, wavelength of $632.8 \mathrm{~nm}$, and observation angle of $173^{\circ}$ (Non-Invasive Back Scatter). Measurements were performed in an aqueous solution, pH 2. PAA solutions were filtered through a $0.45 \mu \mathrm{m}$-pore-size filter (Minisart NML, Sartorius, Göttingen, Germany) before measurement.

\subsubsection{Gel Permeation Chromatography (GPC/SEC)}

The weight-average molecular weight $\left(M_{w}\right)$, number-average molecular weight $\left(M_{n}\right)$, and Z-average radius of gyration $\left(R_{g}\right)$ of linear non-irradiated PAA and OAA were determined by GPC/SEC triple detection system: multiangle laser light scattering detector (Brookhaven Instruments Corporation, Holtsville, NY, USA) and combo refractive indexviscometry detector (Testa Analytical Solutions, Berlin, Germany). Suprema Lux analytical Linear XL column (suitable for neutral and anionic polymers) with Suprema Lux analytical 
SDV precolumn were used in all experiments (PSS Polymer Standards Service GmbH, Mainz, Germany).

GPC measurements were performed in a buffer, passed through a paper filter, of $0.1 \mathrm{~mol} \mathrm{dm}^{-3} \mathrm{Na}_{2} \mathrm{HPO}_{4}, \mathrm{pH} 9.4$, that ensured a compact conformation of polyelectrolyte macromolecules and reduced interactions between the sample and column [66]. Flow rate and temperature were maintained at $1 \mathrm{~cm}^{3} \mathrm{~min}^{-1}$ and $30 \pm 0.1^{\circ} \mathrm{C}$, respectively. PAA solutions were filtered through a $0.45 \mu \mathrm{m}$-pore-size filter (Minisart NML, Sartorius, Göttingen, Germany) before measurement.

\subsubsection{Viscosity Measurements}

The critical hydrodynamic concentrations $\left(c^{*}\right)$ for PAA solutions at various $\mathrm{pH}$ in the range 2-9 were determined using viscosity measurements at $25.0 \pm 0.1^{\circ} \mathrm{C}$. Automatic viscometry system AVS-310 (Schott Geräte, Mainz, Germany) with a set of Ubbelohde viscometers was employed. The critical hydrodynamic concentrations $\left(c^{*}\right)$ were calculated as the reciprocal of the intrinsic viscosity.

\subsection{Irradiation of PAA Solutions and Model Compounds, Recording the Kinetic Data}

2.4.1. Pulse Radiolysis in a Flow System

Argon- or nitrous oxide-saturated aqueous substrate solution was circulated at $0.3 \mathrm{~cm}^{3} \mathrm{~s}^{-1}$ in a gas-tight closed-loop system, flowing through a quartz irradiation cell of $0.7 \mathrm{~cm}^{3}$ volume and optical path of $10 \mathrm{~mm}$, where it was irradiated by short pulses of $6 \mathrm{MeV}$ electrons from an ELU-6 linear accelerator (Elektronika, Moscow, Russia) [15]. Pulse duration was varied within 7-17 ns. Radiation-induced reactions were followed by time-resolved spectroscopic detection based on a Xenon lamp, monochromator, and photomultiplier $[67,68]$. Formation and decay of radicals derived from PAA, OAA, or PA were observed at $\lambda=280 \mathrm{~nm}$ at room temperature. Each recorded trace (corresponding to one data point in half-life or rate constant plots) is an average of up to 8 single-pulse traces, depending on the signal quality. Absorbed dose of ionizing radiation per pulse was in the range of 11-67 Gy, as determined by thiocyanate dosimetry [69].

\subsubsection{Pulse Radiolysis in a Stand-Alone Cell}

Data presented in Figure 3b, due to the very long radical lifetimes at neutral and alkaline $\mathrm{pH}$, could not be collected in a flow system (even at stopped flow the results could have been distorted by diffusion). In this experiment aqueous $\mathrm{N}_{2} \mathrm{O}$-saturated $10 \mathrm{mmol} \mathrm{dm}^{-3}$ PAA solutions of different $\mathrm{pH}$ in the range $2-10$ were pulse-irradiated in a stand-alone gas-tight quartz cell of $10 \mathrm{~mm}$ optical path, containing $1 \mathrm{~cm}^{3}$ of solution, with a maximum of 8 accumulated pulses for a given liquid sample. Optical detection system was the same as described in Section 2.4.1.

\section{Results and Discussion}

\subsection{Physicochemical Properties of the Studied Systems}

The main object of our study was high-molecular-weight PAA of a nominal $M_{w}=450 \mathrm{kDa}$. Two other compounds used as models in some experiments were oligo (acrylic acid) (OAA) and propionic acid (PA).

\subsubsection{Molecular Weights and Dimensions of PAA and OAA}

The polymeric substrates of our study, PAA and OAA, were characterized by GPC to determine their basic physicochemical parameters. Results listed in Table 1 indicate that the obtained $M_{w}$ values were not very far from the nominal ones. The $M_{w} / M_{n}$ ratios of above 3 indicate that samples were polydisperse. The Z-average $R_{g}$ was around $100 \mathrm{~nm}$ for PAA and below the detection limit of $10 \mathrm{~nm}$ for OAA. It should be noted that the $R_{g}$ values are valid in the solvent used for molecular weight determination by GPC and may differ from $R_{g}$ at $\mathrm{pH} 2$, for which most of the kinetic measurements were performed, despite the fact that in both these conditions the PAA chains are expected to be in the 
coiled conformation (while the buffer used as the eluent is of high $\mathrm{pH}$, it provides high ionic strength, and high ion concentration screens the repulsive forces between dissociated carboxylate groups along the chain). Dynamic light scattering measurements on our PAA in water at $\mathrm{pH} 2$ yielded a hydrodynamic radius, $R_{h}$, of $29 \mathrm{~nm}$. Assuming a typical $R_{g} / R_{h}$ ratio for polydisperse statistical polymer coils to be about 1.8 [70], this would yield an estimate of about $52 \mathrm{~nm}$ as $R_{g}$ at $\mathrm{pH}$ 2, i.e., significantly lower than in the buffer.

Table 1. Physicochemical parameters of PAA and OAA used in this study, measured by GPC/SEC method, buffer of $0.1 \mathrm{~mol} \mathrm{dm}^{-3} \mathrm{Na}_{2} \mathrm{HPO}_{4}, \mathrm{pH} 9.4$.

\begin{tabular}{ccc}
\hline Parameters & PAA, Nominal $\boldsymbol{M}_{\boldsymbol{w}} \mathbf{4 5 0} \mathbf{~ k D a}$ & OAA, Nominal $\boldsymbol{M}_{\boldsymbol{w}} \mathbf{1 . 8} \mathbf{~ k D a}$ \\
\hline$M_{w}[\mathrm{kDa}]$ & 555 & 3.073 \\
$M_{n}[\mathrm{kDa}]$ & 182 & 0.844 \\
$M_{w} / M_{n}$ & 3.05 & 3.64 \\
Z-average $R_{g}[\mathrm{~nm}]$ & 99 & $<10$ \\
\hline
\end{tabular}

\subsection{2. $\mathrm{pH}$ and Degree of Dissociation of Carboxylic Groups}

Since our intent is to study recombination of radicals randomly located at the chains of non-ionized poly(acrylic acid), appropriate $\mathrm{pH}$ should be chosen. It should be low enough to provide a nearly complete protonation of carboxylate groups, but, on the other hand, too low $\mathrm{pH}$ is known to cause aggregation of PAA resulting from the formation of mutual hydrogen bonds between two protonated groups [45]. Based on literature data and our own experience, $\mathrm{pH} 2$ still provides molecular dissolution of PAA. It is of interest to estimate the degree of dissociation of our polyelectrolyte at this $\mathrm{pH}$.

While $\mathrm{pK}_{\mathrm{a}}$ for the low-molecular-weight model of PAA, propionic acid, is 4.9 [71], due to the known effects exerted by one dissociated carboxylate group on the dissociation of the neighboring groups, the average $\mathrm{pK}_{\mathrm{a}}$ of the polymer is considerably shifted and has been determined to be about $6.2 \pm 0.2[72,73]$. The same effects do not allow the standard form of the Henderson-Hasselbalch equation to be used to corelate the dissociation degree $\alpha$ to the solution $\mathrm{pH}$. Instead, for polyelectrolytes, a modified version of this equation is recommended (Equation (1), where $n$ is a constant) [73,74].

$$
\mathrm{pH}=\mathrm{pK}_{\mathrm{a}}+n \log \frac{a}{1-a}
$$

For PAA, the $n$ has been found to be $2.0[46,73]$. While Equation (1) provides most precise data in the medium alpha range, we use it here to estimate the dissociation degree of PAA at $\mathrm{pH}$ 2. The obtained value was 0.008 ; therefore, we consider this fraction of dissociated groups as sufficiently low to have a very limited influence on the recombination kinetics. Moreover, the average hydrodynamic radius of our long-chain PAA at this $\mathrm{pH}$ was only $29 \mathrm{~nm}$. If we compare this value to the expected average contour length of these chains, which, based on $M_{n}$, can be estimated at $630 \mathrm{~nm}$, it is clear that PAA chains at $\mathrm{pH} 2$ were in the coiled state, in contrast to the rod-like conformation expected when the negative charges of dissociated groups exert strong Coulombic repulse forces on each other, forcing the macromolecule to stretch. We will therefore neglect the presence of dissociated groups in our considerations related to PAA at $\mathrm{pH} 2$.

\subsubsection{Critical Hydrodynamic Concentrations}

Since our aim was to study the recombination reactions in the dilute regime, where the polymer coils do not interpenetrate, it was necessary to check at which concentration ranges were the above conditions fulfilled for our PAA and OAA samples. The upper limit of concentration has been determined as the critical hydrodynamic concentration, $c^{*}$, using viscometry, as described in Section 2.3.3. Values of $c^{*}$ for PAA and OAA are shown in Figure 2. 


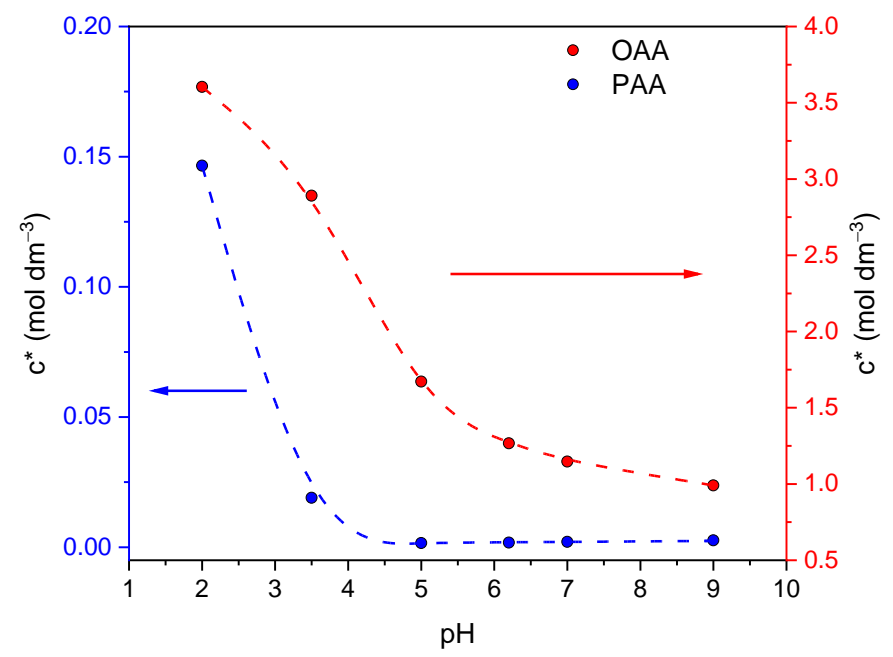

Figure 2. Critical hydrodynamic concentration $\left(c^{*}\right)$ of PAA and OAA in aqueous solutions as a function of $\mathrm{pH}$, as determined by viscometry at $25.0 \pm 0.1^{\circ} \mathrm{C}$.

It is evident that the concentration at which the macromolecules start to overlap decreased strongly with increasing $\mathrm{pH}$. This is expected since, due to increasing linear charge density with raising degree of dissociation, the conformation of chains changes from relatively compact coils that occupy a small space to extended, rigid rods. For our kinetic study the values at $\mathrm{pH} 2$ are of importance. We see that, in order to work on a system where coils do not interpenetrate, one cannot exceed around $140 \mathrm{mmol} \mathrm{dm}^{-3}$ for PAA and $3.5 \mathrm{~mol} \mathrm{dm}^{-3}$ for the much smaller molecules of OAA. To fulfill this condition, in our experiments PAA and OAA concentrations up to $50 \mathrm{mmol} \mathrm{dm}^{-3}$ were used.

\subsection{Generation and Detection of Free Radicals}

Ionizing radiation is known as a clean and easy to control way to generate polymer radicals [75-77]. In dilute aqueous solutions, practically all the radiation energy is absorbed by water. Radiolysis of water leads to the formation of various short-lived, highly reactive intermediates [78-80]. At the timescales when reactions with solutes present in millimolar concentrations are possible, the main reactive species are hydroxyl radicals, hydrogen atoms, and hydrated electrons (reaction 2). Their radiation-chemical yields, in the units of $10^{-7} \mathrm{~mol} \mathrm{~J}^{-1}$, are $2.8,0.6$, and 2.8 , respectively. In acidic solutions, hydrated electrons are converted to hydrogen atoms (reaction $3, k=2.3 \times 10^{10} \mathrm{dm}^{3} \mathrm{~mol}^{-1} \mathrm{~s}^{-1}$ [81]). In order to increase the yield of hydroxyl radicals, it is customary to saturate solutions with nitrous oxide, which transforms $\mathrm{e}_{\mathrm{aq}}{ }^{-}$into ${ }^{\bullet} \mathrm{OH}$ (reaction $4, k=9.1 \times 10^{9} \mathrm{dm}^{3} \mathrm{~mol}^{-1} \mathrm{~s}^{-1}$ [82]). However, in acidic solutions the efficiency of the latter process is limited by the competing reaction (3).

$$
\begin{gathered}
\mathrm{H}_{2} \mathrm{O} \rightarrow{ }^{\bullet} \mathrm{OH}, \mathrm{H}^{\bullet}, \mathrm{e}_{\mathrm{aq}}{ }^{-}, \mathrm{H}_{2} \mathrm{O}_{2}, \mathrm{H}_{2}, \mathrm{H}_{3} \mathrm{O}^{+} \\
\mathrm{H}_{3} \mathrm{O}^{+}+\mathrm{e}_{\mathrm{aq}}{ }^{-} \rightarrow \mathrm{H}^{\bullet}+\mathrm{H}_{2} \mathrm{O} \\
\mathrm{N}_{2} \mathrm{O}+\mathrm{e}_{\mathrm{aq}}{ }^{-}+\mathrm{H}_{2} \mathrm{O} \rightarrow{ }^{\bullet} \mathrm{OH}+\mathrm{OH}^{-}+\mathrm{N}_{2}
\end{gathered}
$$

Hydroxyl radicals and hydrogen atoms are known to react with PAA by hydrogen abstraction, a process that leads to the formation of two types of carbon-centered radicals, $\alpha$ and $\beta$, located randomly along PAA chains (reaction 5). While the rate constants of ${ }^{\bullet} \mathrm{OH}$ attack on macromolecules may depend on both molecular weight and concentration [83], for conditions similar to our work a value of $k=9 \times 10^{7} \mathrm{dm}^{3} \mathrm{~mol}^{-1} \mathrm{~s}^{-1}$ has been reported 
for the protonated PAA, and $k=2.2 \times 10^{8} \mathrm{dm}^{3} \mathrm{~mol}^{-1} \mathrm{~s}^{-1}$ for the deprotonated chains, the reaction of $\mathrm{H}^{\bullet}$ being somewhat slower [53].

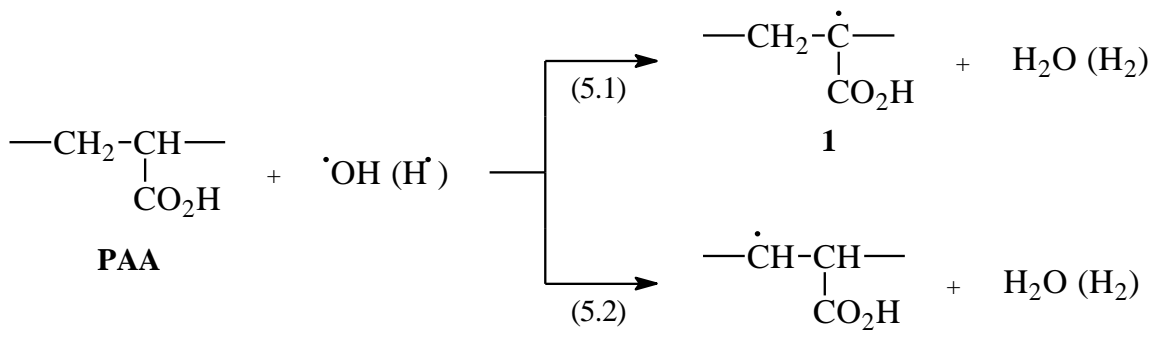

2

Previous studies indicate that initially around $30 \%$ of $\alpha$-radicals $\mathbf{1}$ and $70 \%$ of $\beta$ radicals 2 are formed (reactions 5.1 and 5.2, respectively) [50]. These radicals, when in the protonated forms, show a featureless spectrum in UV, with absorbance raising towards shorter wavelengths $[50,53,54]$. Since no spectral evolution is observed during their decay at low $\mathrm{pH}$, it is inferred that that the reactivity of $\alpha$-radicals and $\beta$-radicals in recombination reactions is similar; therefore, it can be kinetically considered as a single process.

It should be noted that these reactions, in particular at low polymer concentrations and under pulse radiolysis conditions, have to compete with fast mutual recombination of $\bullet \mathrm{OH}$ radicals and $\mathrm{H}^{\bullet}$ atoms; therefore, one cannot expect that all ${ }^{\bullet} \mathrm{OH}$ and $\mathrm{H}^{\bullet}$ formed in the system would finally yield PAA radicals. Pulse radiolysis experiments performed at $\mathrm{pH} 2$ in $10 \mathrm{mmol} \mathrm{dm}^{-3}$ PAA solutions saturated with argon or nitrous oxide subjected to an electron pulse of $67 \mathrm{~Gy}\left(1 \mathrm{~Gy}=1 \mathrm{~J} \mathrm{~kg}^{-1}\right.$ ) (see Figure A1b in the Appendix A) indicate that the radiation-chemical yields of PAA radicals, expressed in mol of the product per $1 \mathrm{~J}$ of energy absorbed, were around $2.7 \times 10^{-7}$ and $3.1 \times 10^{-7}$, respectively, while the sum of radiation yields of ${ }^{\bullet} \mathrm{OH}, \mathrm{H}^{\bullet}$, and $\mathrm{e}_{\mathrm{aq}}{ }^{-}$was $6.2 \times 10^{-7}$. It should be noted that the yields of PAA radicals depend on polymer concentrations; for $50 \mathrm{mmol} \mathrm{dm}^{-3}$, the yields in $\mathrm{Ar}$ and $\mathrm{N}_{2} \mathrm{O}$ saturated solutions at comparable doses increased to $4.7 \times 10^{-7}$ and $5.4 \times 10^{-7} \mathrm{~mol} \mathrm{~J}^{-1}$, respectively. The molar absorption coefficient at $\lambda=280 \mathrm{~nm}$, determined by comparing the observed absorbance of radicals in Ar-saturated $50 \mathrm{mmol} \mathrm{dm}^{-3}$ PAA with yields calculated from stochastic simulations using the known rate constants of reactions in the system (see Appendix A), was $\varepsilon=590 \pm 30 \mathrm{dm}^{3} \mathrm{~mol}^{-1} \mathrm{~cm}^{-1}$.

\subsection{Radical Lifetime as a Function of $p H$}

Carbon-centered PAA radicals can undergo a number of reactions ([50], for a general discussion on polymer radical reactions see also [16]). Those involving one radical include H-transfer, which leads to transformation of $\beta$-radicals into the more stable $\alpha$-radicals, as well as $\beta$-fragmentation leading to chain scission. Both these processes are relatively slow, and they show up with considerable yields only in neutral and alkaline solutions, when the lifetime of PAA radicals is long (see below). A potential reaction of PAA radical with hydrogen peroxide formed by ${ }^{\bullet} \mathrm{OH}$ self-combination (due to incomplete scavenging of - OH radicals by PAA at the lowest polymer concentrations used in this work) is also too slow to compete with reactions between two polymer radicals, at least in an acidic medium. Reactions involving two PAA radicals (recombination) are crosslinking and disproportionation. Crosslinking results in formation of a C-C covalent bond between the former radical sites, while disproportionation does not create a crosslink, but a double bond on one of the former radical sites. The ratio between crosslinking and disproportionation is largely set by the polymer chemistry and cannot be easily influenced. Studies on 2,4-dimethylglutaric acid used as a structural model of PAA indicate that in acidic solution the fraction of crosslinking events is around 44\%, indicating the importance of the disproportionation pathway [84]. Since the rate-determining step of crosslinking and disproportionation is the same, i.e., coming of two radical-bearing chain segments into proximity, in kinetic studies we do not differentiate between them, considering them as two kinetically equivalent 
components of radical decay, and we use the term "recombination" to denote the sum of these processes. The two latter reactions are the only processes leading to a decrease in the radical concentration in the system, since in the previously mentioned $\mathrm{H}$-transfer and chain scission the number of radicals is preserved, and the potential radical transfer back to the solvent is thermodynamically unfavorable. Therefore, the lifetime of polymer radicals depends to a large extent on how easy it is for two radical-bearing chain segments to approach each other. In polyelectrolytes, in the absence of other factors such as steric barriers, this depends mainly on the presence and strength of repulsive electrostatic interactions between chain segments due to the ionized functional groups. Already in the 1970s Görlich and Schnabel demonstrated such an effect by studying radical decay in copolymers of vinyl alcohol and acrylic acid [85]. The increasing fraction of dissociated acrylic acid units led to a significant decrease in the radical recombination rate. In previous studies on PAA homopolymers, a strong $\mathrm{pH}$ effect on the radical lifetime has been reported [50,52]. Lifetimes observed for fully charged PAA were several orders of magnitude longer than for the case of protonated carboxylic groups. Very long lifetimes of radicals derived from fully charged polyelectrolytes have also been found for poly(methacrylic acid) [86] and poly(styrene sulfonate) [87].

In our study we have confirmed this earlier observation by pulse-irradiating oxygenfree solutions of PAA, OAA, and PA at various $\mathrm{pH}$ and following the decay of substratederived radicals. Already from the kinetic traces of PAA radicals (Figure 3a) it is evident that at $\mathrm{pH} 2$ the radicals decayed fast. Their first half-life was less than a millisecond. In contrast, no decay was detectable on the same timescale for $\mathrm{pH} 5$ and 9; actually, even some increase was observed resulting from the slow $\mathrm{H}$-transfer taking place. The same effect, albeit less pronounced, was observed for OAA (Figure 4a). For propionic acid (Figure 4b), radical decay was observed within the first millisecond at all $\mathrm{pH}$ values, although the fastest reaction was still seen at $\mathrm{pH}$ 2. Please note that in Figures $3 \mathrm{a}$ and $4 \mathrm{a}, \mathrm{b}$ the absorbance has been normalized, taking the value just after the pulse as 1 , to compensate for differences in free radical yields and their molar absorption coefficients at different $\mathrm{pH}$. To illustrate the magnitude of the charge density effect on radical decay, observed half-lives of PAA radicals, determined by pulse radiolysis and by time-resolved conventional spectrophotometric measurements, are shown in Figure $3 \mathrm{~b}$ as a function of $\mathrm{pH}$. Decay of PAA radicals on fully charged chains was six orders of magnitude slower than that on non-charged chains at $\mathrm{pH} 2$.

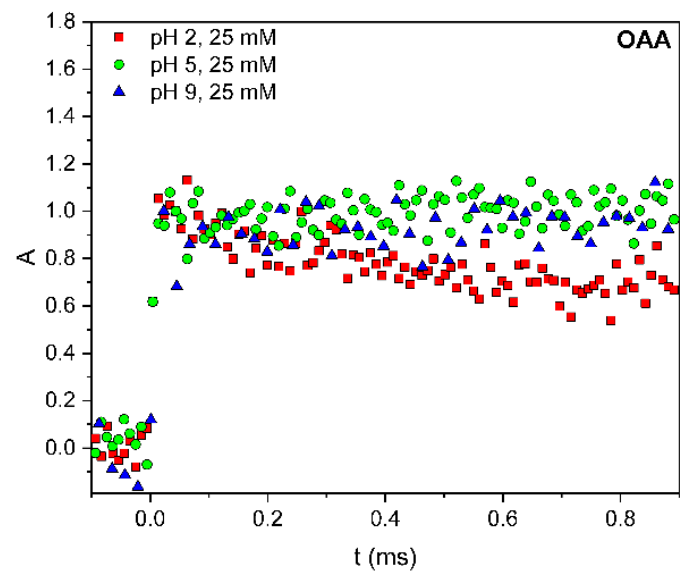

(a)

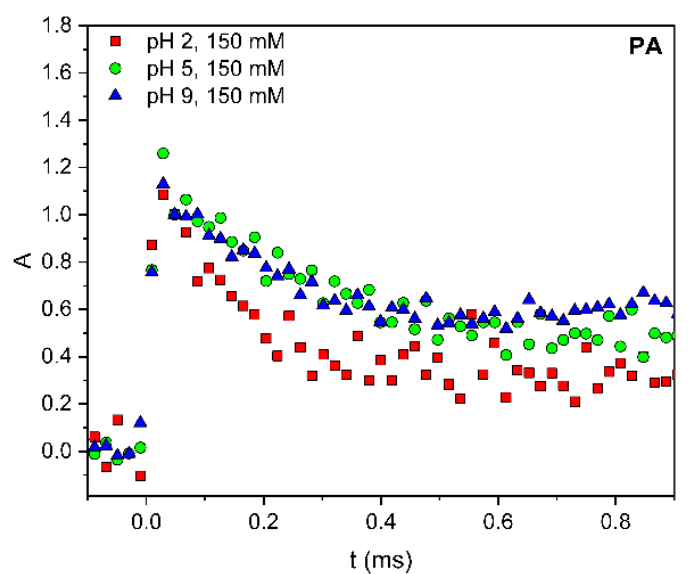

(b)

Figure 3. (a) Pulse radiolysis of $\mathrm{N}_{2} \mathrm{O}$-saturated aqueous solutions containing $25 \mathrm{mmol} \mathrm{dm}^{-3}$ poly(acrylic acid) at various $\mathrm{pH}$. Normalized absorbance at $\lambda=280 \mathrm{~nm}$ as a function of time after pulse. Dose per pulse around $60 \mathrm{~Gy}$. (b) Half-life of PAA radicals in $\mathrm{N}_{2} \mathrm{O}$-saturated aqueous solutions containing $10 \mathrm{mmol} \mathrm{dm}{ }^{-3} \mathrm{PAA}$ as a function of $\mathrm{pH}$, and schemes depicting the change in polymer conformation. 


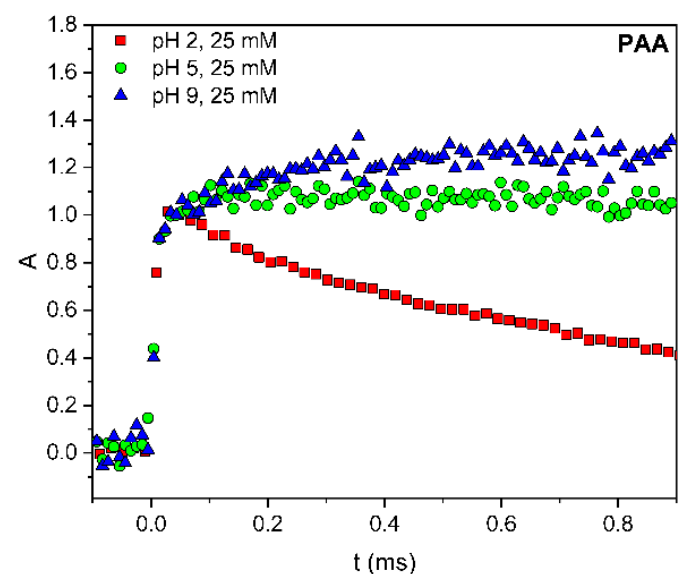

(a)

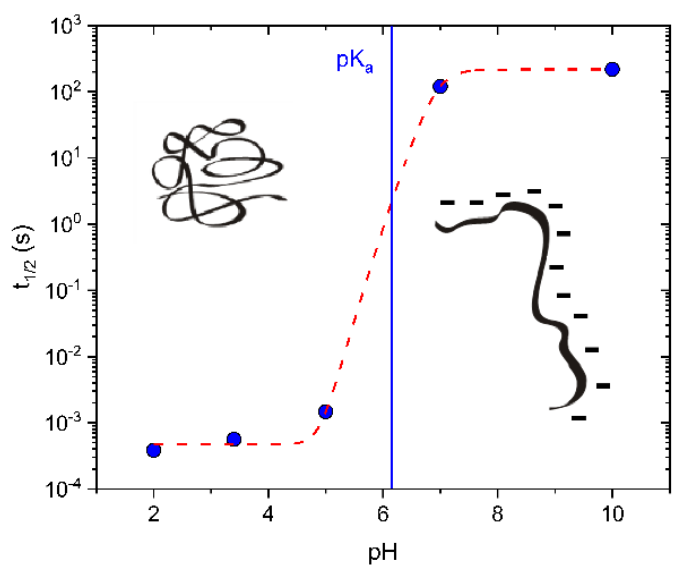

(b)

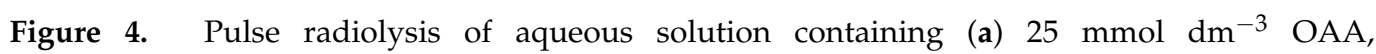
(b) $150 \mathrm{mmol} \mathrm{dm}{ }^{-3} \mathrm{PA}$ at various $\mathrm{pH}$, dose per pulse around $60 \mathrm{~Gy}$. Normalized absorbance at $\lambda=280 \mathrm{~nm}$ as a function of time after pulse. Solutions at $\mathrm{pH} 2$ saturated with $\mathrm{Ar}$, at $\mathrm{pH} 5$ and 9 saturated with $\mathrm{N}_{2} \mathrm{O}$.

\subsection{Radical Decay Kinetics at $\mathrm{pH} 2$ \\ 3.4.1. Kinetic Traces}

In our further study we concentrate on decay of radicals on fully protonated PAA chains at $\mathrm{pH} 2$. These kinetics have some interesting features. We shall consider that while at moderate pulses of ionizing radiation, such as used in this study, it is improbable to find more than one radical at the same OAA or PA molecule, it is quite probable to find several radicals generated by the same pulse on a PAA chain. As a consequence, we may have two different modes of recombination: intermolecular (between two radicals on two different macromolecules) and intramolecular (between two radicals located on the same chain). For flexible polymer chains, intramolecular recombination is expected to be fast, facilitated by the initial proximity of radicals located at the same chain.

Recombination of two radicals is, in general, expected to follow second-order kinetics. However, it has been demonstrated in a number of experimental [55,88-91], MonteCarlo $[92,93]$, and deterministic $[94,95]$ simulation studies that recombination of polymerbound radicals in solution may deviate from classical second-order equations, in contrast to chemically identical radicals of their low-molecular-model compounds. The apparent momentary rate constant is often observed to decrease in the course of the reaction. This behavior seems to be typical for intramolecular recombination, when initially many radicals are located on each chain. A model that has been found to describe such cases well is dispersive kinetics (Equation (6), which for reactions of the A+A type takes the form of Equation (7)), where $k(t)$ is the momentary rate constant, $B$ and $\alpha$ are parameters, $c(t)$ is the substrate concentration at time $t$, and $c_{0}$ is the initial substrate concentration [96,97]. For $\alpha=1$ this model is reduced to the classical homogeneous kinetics with $k$ independent of time. Deviation of $\alpha$ from 1 is a measure of reactivity dispersion in the system. It has been demonstrated that this dispersion stems from the initial distribution of interradical distances along the chain (this distance being the main factor governing the reaction rate) and subsequent change in this distribution during reaction [92].

$$
\begin{gathered}
k(t)=B t^{\alpha-1} \\
\frac{1}{c(t)}-\frac{1}{c_{0}}=\frac{B t^{\alpha}}{\alpha}
\end{gathered}
$$

While systematic analysis of PAA radical reactivity in terms of dispersive kinetics theory is beyond the scope of our study, we have attempted to test if Equation (7) describes the observed decay of PAA radicals more adequately than the regular second-order kinetics, 
in line with earlier observations for doses per pulse much higher than in this work [15,55]. An exemplary test is shown in Figure 5. A typical kinetic trace of PAA radical decay is fit with first-order and second-order kinetic functions, as well as with Equation (7). While it is clear that experimental data fit much better to the second-order than to the first-order kinetic model, under our experimental conditions (molecular weight, $\mathrm{pH}$, concentration range, moderate doses per pulse), fitting with Equation (7) was only slightly better than with the classical second-order kinetics, the $\alpha$ parameter being not far from 1 .

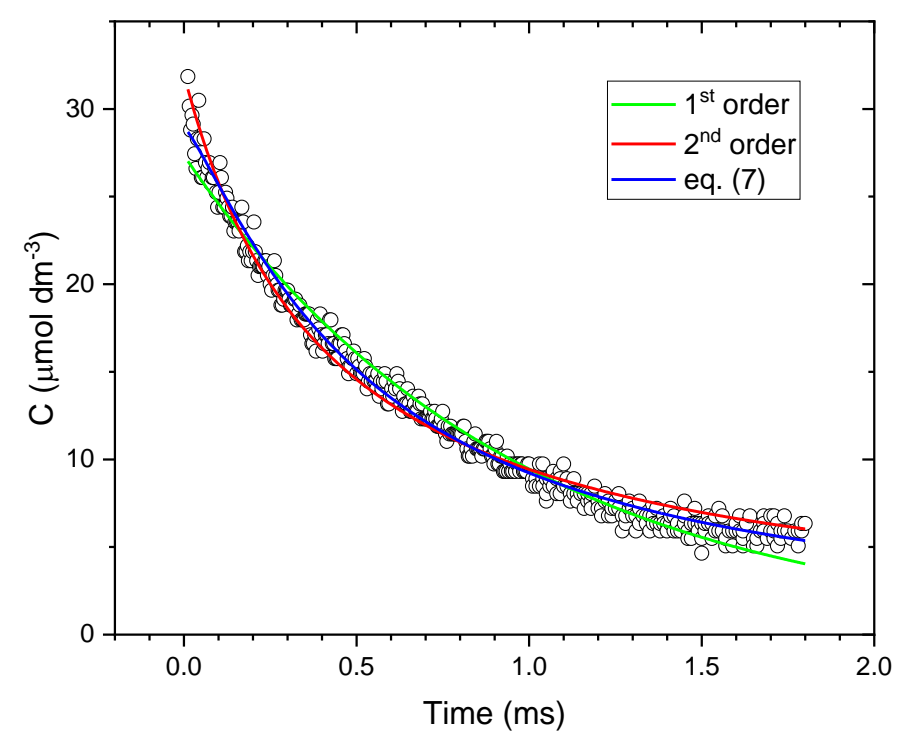

Figure 5. Pulse radiolysis of Ar-saturated aqueous solution containing $50 \mathrm{mmol} \mathrm{dm}^{-3} \mathrm{PAA}, \mathrm{pH} 2$, dose per pulse $62 \mathrm{~Gy}$, average initial number of radicals on a chain 1.64. Experimental data on the decay of the PAA radicals and the fits based on three kinetic models: classical first- and second-order, and dispersive model (Plonka model, Equation (7)).

\subsubsection{Radical Recombination Rate Constants and Their Dependence on Experimental} Parameters

Second-order kinetics stipulates that the reciprocal half-life of radicals should be directly proportional to the initial radical concentration. In Figure 6 results of kinetic analysis for decay of PAA radicals have been presented in the second-order coordinates, for various polymer concentrations $\left(2.5-50 \mathrm{mmol} \mathrm{dm}{ }^{-3}\right.$ in the terms of monomer units). While there is considerable scatter in the data, especially for the lowest PAA concentrations (due to the low molar absorption coefficient and low yield of polymer radicals resulting from strong competition of mutual ${ }^{\bullet} \mathrm{OH}$ and $\mathrm{H}^{\bullet}$ recombination, resulting in weak signals), the data can be approximated with linear functions, and the slopes correspond to the second-order rate constant $2 k$. While for the highest polymer concentrations used in this study (10-50 mmol dm${ }^{-3}$ ) the slopes were similar, below this concentration range the slope tended to increase with decreasing PAA concentration, indicating an increase in the recombination rate constant of radicals. Such an effect was not observed for OAA and PA (data not shown).

This observation can be explained by the fact that if a constant concentration of polymer radicals is created in the system by electron pulse, then the lower polymer concentration, the higher average initial number of radicals on each macromolecule. This is illustrated in Figure 7, where the observed second-order rate constant calculated for each experiment (i.e., for each combination of dose and polymer concentration) is plotted as a function of average initial number of radicals on a chain, $Z_{R 0}$. 


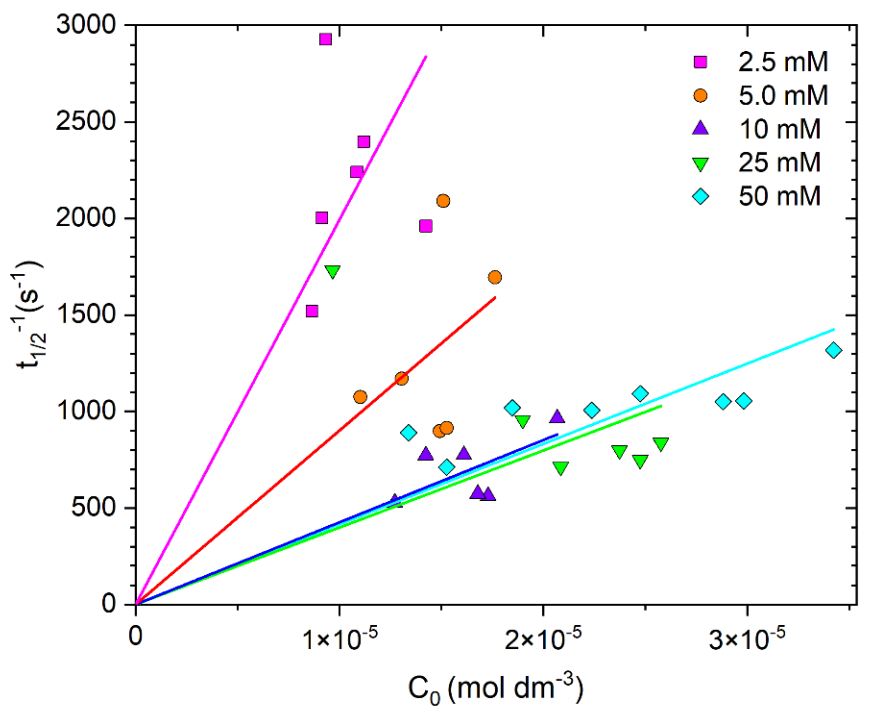

Figure 6. Kinetic analysis for decay of PAA radicals observed during pulse radiolysis of Ar-saturated aqueous solutions containing $2.5-50 \mathrm{mmol} \mathrm{dm}^{-3} \mathrm{PAA}, \mathrm{pH} 2$, dose per pulse 11-67 Gy. Reciprocal half-life of radicals as a function of the initial radical concentration $\mathrm{c}_{0}$. Polymer concentrations, in mmol dm $\mathrm{dm}^{-3}$ of monomer units, are given in the graph.

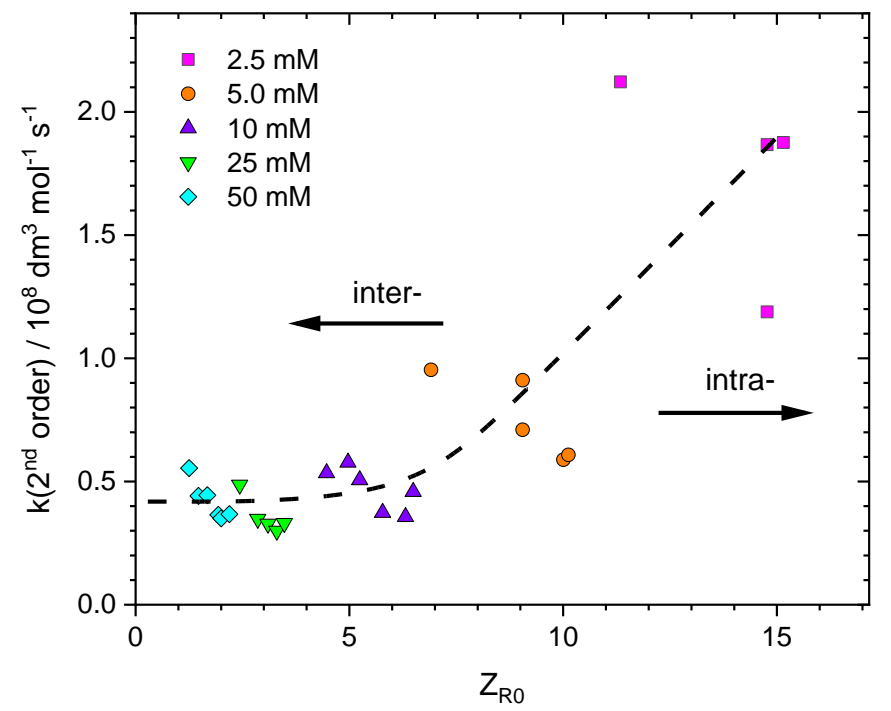

Figure 7. Kinetic analysis for decay of PAA radicals observed during pulse radiolysis of Ar-saturated aqueous solutions containing 2.5-50 mmol dm ${ }^{-3}$ PAA, pH 2, dose per pulse 11-67 Gy. Second-order rate constant calculated for each experiment as a function of average initial number of radicals on a chain. Polymer concentrations, in $\mathrm{mmol} \mathrm{dm^{-3 }}$ of monomer units, are given in the graph.

It is clear that, in contrast to Figure 6, here all data points for various polymer concentrations can be described by a single dependence, notwithstanding the data scatter at 2.5 and $5 \mathrm{mmol} \mathrm{dm}^{-3}$. It seems that indeed the average number of radicals per chain is the decisive factor governing the radical decay kinetics. When this number is low, radicals decay mainly by intermolecular recombination. However, for $Z_{R 0}$ higher than around 5 , there is a distinct upward tendency in the rate constant, which can be attributed to the fact that if many radicals are located simultaneously on each chain, their main mode of recombination is the reaction with their neighbors at the same macromolecule. The lower the interradical distance along the chain, the faster the reaction, since the radicals in proximity require rearrangements of shorter chain segments. These findings are in line with earlier experimental data on radicals of poly(ethylene oxide) [89] and, when 
intramolecular recombination is concerned, also with Monte Carlo simulations by the Cooperative Motion Algorithm [92]. The absence of such effect for OAA and PA is due to the fact that at the dose and concentration ranges used in this study, the average number of radicals generated on molecules of these compounds is always much lower than one, so intermolecular recombination is the only reaction mode.

\subsubsection{Rate-Determining Step in Intermolecular Recombination of PAA Radicals}

Data at the low $Z_{R 0}$ limit of Figure 7, where intermolecular recombination dominates, can be used to determine the rate-controlling step of radical decay in dilute polymer solutions, where the coils are separated by void volumes of the solvent and each radical bears only one radical site. Such analysis may also be relevant to the termination step of free radical polymerization in dilute solutions. In principle, three steps can be considered in intermolecular recombination: translational diffusion of the coils until they collide, segmental diffusion needed for the two radical-bearing segments of two separate macromolecules to come into contact, and the chemical reaction itself (Figure 8). The latter is not probable as the rate-determining step since the typical rate constants for recombination of aliphatic low-molecular-weight radicals, including protonated carboxylic acids, are significantly higher $\left(>4 \times 10^{8} \mathrm{dm}^{3} \mathrm{~mol}^{-1} \mathrm{~s}^{-1}[84,98]\right)$ than the values observed here.

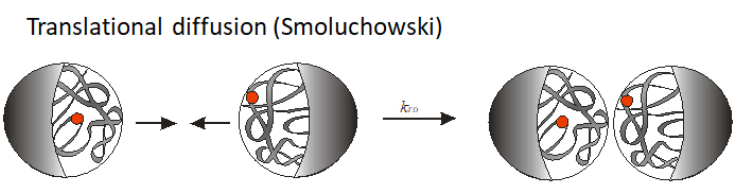

Segmental diffusion

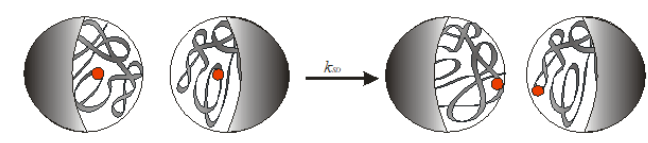

Chemical reaction

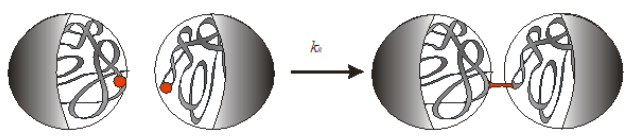

Figure 8. Schematic interpretation of intermolecular recombination steps: translational diffusion of the coils, segmental diffusion, and chemical reaction (crosslinking) of polymer radicals.

Based on the Smoluchowski equation for the second-order rate constant of a reaction between two identical spherical reagents controlled by translational diffusion (Equation (8), $[14,99,100])$, where $R$ is the reaction radius of a sphere and $D$ is its diffusion coefficient, we can estimate the expected rate constant for such process in our case.

$$
k=16 \pi R D N_{A}
$$

Diffusion coefficient and hydrodynamic radius of our PAA at $\mathrm{pH} 2$, as determined by dynamic light scattering, are $8.5 \times 10^{-8} \mathrm{~cm}^{2} \mathrm{~s}^{-1}$ and $29 \mathrm{~nm}$, respectively. Assuming $R=R_{h}$ and substituting these values into Equation (8), we obtain an expected rate constant for translational diffusion-controlled reaction as $7.5 \times 10^{9} \mathrm{dm}^{3} \mathrm{~mol}^{-1} \mathrm{~s}^{-1}$, i.e., much higher than the experimental values for low $Z_{R 0}$ (Figure 7). This comparison indicates that, most probably, the rate-determining step in intermolecular recombination of radicals in dilute polymer solution is not translational diffusion but segmental diffusion, causing the radical-bearing segments to be exposed for reaction in the case of collision.

\section{Conclusions}

Recombination of radicals derived from poly(acrylic acid) and model compounds in oxygen-free dilute aqueous solutions has been studied by pulse radiolysis with spec- 
trophotometric detection. Strong dependence of radical lifetime on $\mathrm{pH}$ confirms earlier observations of this phenomenon; the magnitude of $\mathrm{pH}$ effect is greatly diminished for oligo(acrylic acid) and propionic acid, which is related to the relative strength of repulsive Coulombic forces acting between the radicals located on long chains, short chains, and low-molecular-weight model. At pH 2, which is the lowest value at which the measurements are feasible to avoid extensive aggregation, the degree of dissociation is below $1 \%$, and the radicals recombine relatively fast; at the applied experimental conditions the lifetime is on the order of $1 \mathrm{~ms}$. Linear dependence of reciprocal half-life on the initial radical concentration and good fit of the kinetic traces by the second-order kinetic function indicate that the process is generally of second order. Still, somewhat better fit using a dispersive kinetics model suggests some, albeit moderate, dispersion of reactivity, which may be caused by specific features of intramolecular recombination and/or molecular weight distribution. An interesting observation is that while for a constant polymer concentration the second-order kinetic plot is linear, such plots for different concentrations (all being well below the critical hydrodynamic concentrations) start to diverge from each other at PAA concentrations below $10 \mathrm{mmol} \mathrm{dm}^{-3}$ (in terms of monomer units), and the apparent rate constant increases with decreasing polymer concentrations. This effect can be explained by evoking the concept of initial average number of radicals per chain, $Z_{R 0}$, as the decisive factor in radical decay kinetics. When the rate constant values are plotted against $Z_{R 0}$, they all converge to a single relationship, which is stable in the low $Z_{R 0}$ range, but starts to increase when this parameter is higher than about five. This effect is explained by transition between two dominating recombination modes: intermolecular when there are, on average, few radicals per chain and intramolecular when many radicals are present. The positive correlation between the rate constant and $Z_{R 0}$ reflects the fact that the rate of intramolecular recombination on a flexible polymer chain increases with decreasing average interradical distance along the chain, which has been demonstrated before by Monte Carlo simulations and fits well to the earlier observations for radical decay in dilute solutions of poly(ethylene oxide). Comparison of the decay rate constant at the lowest limit of $Z_{R 0}$, i.e., for intermolecular recombination, with the expected rate constant for the reaction controlled by translational diffusion calculated by Smoluchowski equation, demonstrates that experimental values are much lower than expected for this rate control mode. This indicates that the kinetics of intermolecular recombination are most probably governed by chain dynamics.

Author Contributions: Conceptualization, M.M., S.K. and P.U.; methodology, S.K. and P.U.; validation, S.K. and P.U.; formal analysis, M.M., S.K. and P.U.; investigation, M.M. and S.K.; data curation, M.M.; writing—original draft preparation, M.M., S.K. and P.U.; writing—review and editing, M.M., S.K. and P.U.; visualization, M.M., S.K. and P.U.; supervision, S.K. and P.U.; project administration, M.M.; funding acquisition, M.M. All authors have read and agreed to the published version of the manuscript.

Funding: This research was funded by the National Science Centre, Poland, project No. 2017/27/N/ ST4/02536 and by IAEA Coordinated Research Project (CRP) F23035.

Institutional Review Board Statement: Not applicable.

Informed Consent Statement: Not applicable.

Data Availability Statement: Data are available from the corresponding author.

Acknowledgments: The authors thank Krzysztof Hodyr and Paweł Flakiewicz for their skillful technical help in running the pulse radiolysis experiments.

Conflicts of Interest: The authors declare no conflict of interest. The funders had no role in the design of the study; in the collection, analyses, or interpretation of data; in the writing of the manuscript, or in the decision to publish the results. 


\section{Appendix A}

In experiments described in this work, it is of importance to know the concentrations of the radiation-generated polymer-based radicals. For this purpose, their molar absorption coefficient at the analytical wavelength of $280 \mathrm{~nm}$ has to be determined. This can be established by performing a series of experiments when a range of doses of ionizing radiation is applied by electron pulses to the polymer solution, generating various initial concentrations of the water radiolysis products in question $\left({ }^{\bullet} \mathrm{OH}, \mathrm{H}^{\bullet}\right.$ and $\left.\mathrm{e}_{\mathrm{aq}}{ }^{-}\right)$, which then, directly or via intermediate reactions (3) and (4), generate polymer radicals in reaction (5) and its H-mediated analogue. While the radiation-chemical yields of water radiolysis products at various $\mathrm{pH}$ are known or can be easily calculated, this is no longer true for polymer radicals, in particular in dilute solutions. Due to the competition of fast, diffusion-controlled mutual recombination reactions of ${ }^{\bullet} \mathrm{OH}$ and $\mathrm{H}^{\bullet}$, some of those do not reach the macromolecules; thus, the polymer radical yield is lower that the yield of reactive water radiolysis products. In order to calculate the radiation-chemical yield for each of the experiments of the above-mentioned series, a stochastic kinetic simulator Kinetiscope version 1.1.956.x64 was used [101,102]. The list of main reactions taking place and their rate constants are shown in Table A1. A special algorithm has been used to simulate the non-instantaneous generation of ${ }^{\bullet} \mathrm{OH}, \mathrm{H}^{\bullet}$ and $\mathrm{e}_{\mathrm{aq}}{ }^{-}$during the electron pulse. The obtained yields of polymer radicals have been corelated with the corresponding experimental absorbance values (Figure A1a), yielding the molar absorption coefficient of $590 \pm 30 \mathrm{dm}^{3} \mathrm{~mol}^{-1} \mathrm{~cm}^{-1}$.

Table A1. Reactions and their rate constants used in the Kinetiscope simulations aimed at determination of radiationchemical yield of PAA radicals at various experimental conditions.

\begin{tabular}{|c|c|c|}
\hline Reaction & Rate Constant $\left(\mathrm{dm}^{3} \mathrm{~mol}^{-1} \mathrm{~s}^{-1}\right)$ & Source \\
\hline$\cdot{ }^{\bullet} \mathrm{OH}+\mathrm{PAA} \rightarrow(\mathrm{PAA})^{\bullet}+\mathrm{H}_{2} \mathrm{O}$ & $9 \times 10^{7}$ & [53] \\
\hline $\mathrm{H}^{\bullet}+\mathrm{PAA} \rightarrow(\mathrm{PAA})^{\bullet}+\mathrm{H}_{2}$ & $5 \times 10^{6}$ & estimate based on [53] \\
\hline $\mathrm{e}_{\mathrm{aq}}{ }^{-}+\mathrm{H}_{3} \mathrm{O}^{+} \rightarrow \mathrm{H}^{\bullet}+\mathrm{H}_{2} \mathrm{O}$ & $2.3 \times 10^{10}$ & [81] \\
\hline $\mathrm{e}_{\mathrm{aq}}{ }^{-}+\mathrm{N}_{2} \mathrm{O}+\mathrm{H}_{2} \mathrm{O} \rightarrow{ }^{\bullet} \mathrm{OH}+\mathrm{OH}^{-}+\mathrm{N}_{2}$ & $9.1 \times 10^{9}$ & [82] \\
\hline $2 \cdot \mathrm{OH} \rightarrow \mathrm{H}_{2} \mathrm{O}_{2}$ & $5.5 \times 10^{9}$ & [64] \\
\hline $\mathrm{H}^{\bullet}+{ }^{\bullet} \mathrm{OH} \rightarrow \mathrm{H}_{2} \mathrm{O}$ & $7 \times 10^{9}$ & {$[64]$} \\
\hline $2 \mathrm{H}^{\bullet} \rightarrow \mathrm{H}_{2}$ & $8 \times 10^{9}$ & [64] \\
\hline
\end{tabular}

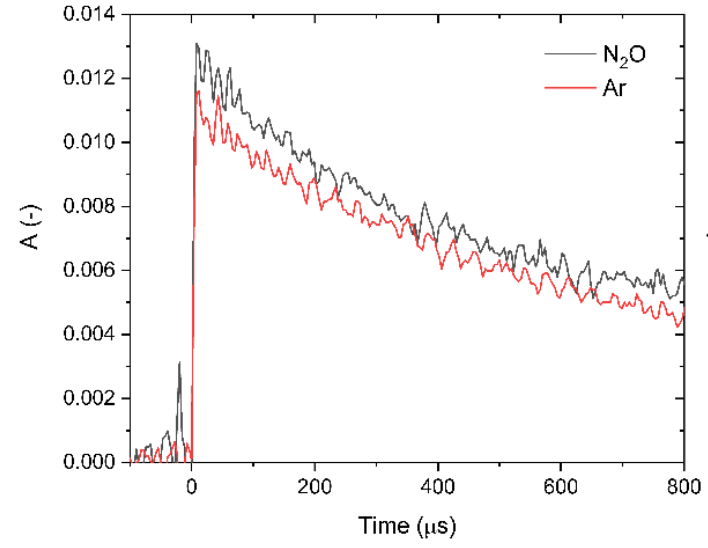

(a)

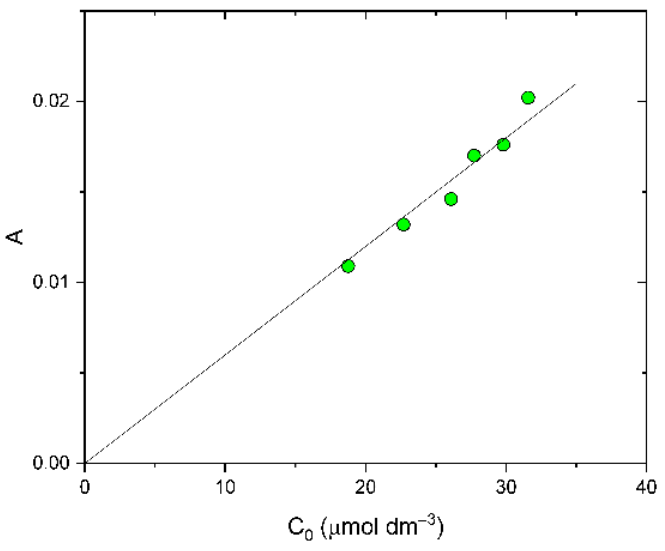

(b)

Figure A1. (a) Pulse radiolysis of Ar-saturated aqueous solution containing $50 \mathrm{mmol} \mathrm{dm}^{-3}$ PAA, $\mathrm{pH}$ 2. Initial absorbance at $\lambda=280 \mathrm{~nm}$ as a function of initial concentration of PAA radicals, $\mathrm{c}_{0}$, calculated by Kinetiscope. (b) Comparison of kinetic traces in $10 \mathrm{mmol} \mathrm{dm}^{-3}$ PAA solutions, $\mathrm{pH} 2$, saturated with argon and nitrous oxide, dose per pulse $67 \mathrm{~Gy}$.

As a support to check the correctness of our simulations, we have run two experiments where $10 \mathrm{mmol} \mathrm{dm}{ }^{-3}$ PAA solutions were saturated either with Ar or with $\mathrm{N}_{2} \mathrm{O}$ and 
irradiated at otherwise the same conditions. The ratio of the polymer radical yield between $\mathrm{N}_{2} \mathrm{O}$ and Ar-saturated solutions as read from the initial absorbance in the kinetic traces (Figure A1b) is 1.15, while simulations yield 1.14, which we consider as fair agreement taking into account the complexity of the system.

\section{References}

1. Matyjaszewski, K. Atom Transfer Radical Polymerization (ATRP): Current Status and Future Perspectives. Macromolecules 2012, 45, 4015-4039. [CrossRef]

2. Siegwart, D.J.; Oh, J.K.; Matyjaszewski, K. ATRP in the design of functional materials for biomedical applications. Prog. Polym. Sci. 2012, 37, 18-37. [CrossRef]

3. Matyjaszewski, K.; Dong, H.; Jakubowski, W.; Pietrasik, J.; Kusumo, A. Grafting from Surfaces for "Everyone": ARGET ATRP in the Presence of Air. Langmuir 2007, 23, 4528-4531. [CrossRef]

4. Chen, M.; Zhong, M.; Johnson, J.A. Light-Controlled Radical Polymerization: Mechanisms, Methods, and Applications. Chem. Rev. 2016, 116, 10167-10211. [CrossRef]

5. Parkatzidis, K.; Wang, H.S.; Truong, N.P.; Anastasaki, A. Recent Developments and Future Challenges in Controlled Radical Polymerization: A 2020 Update. Chem 2020, 6, 1575-1588. [CrossRef]

6. Beuermann, S.; Buback, M. Rate Coefficients of Free-Radical Polymerization Deduced from Pulsed Laser Experiments. Prog. Polym. Sci. 2002, 27, 191-254. [CrossRef]

7. Buback, M. Propagation Kinetics in Radical Polymerization Studied via Pulsed Laser Techniques. Macromol. Symp. 2009, 275-276, 90-101. [CrossRef]

8. Kockler, K.B.; Haehnel, A.P.; Junkers, T.; Barner-Kowollik, C. Determining Free-Radical Propagation Rate Coefficients with High-Frequency Lasers: Current Status and Future Perspectives. Macromol. Rapid Commun. 2016, 37, 123-134. [CrossRef]

9. Marien, Y.W.; Edeleva, M.; van Steenberge, P.H.M.; D’hooge, D.R. Exploiting the Pulsed Laser Polymerization-Size Exclusion Chromatography Technique to Retrieve Kinetic Parameters in Radical Polymerization: State-of-the-Art and Future Challenges. Adv. Chem. Eng. 2020, 56, 59-95. [CrossRef]

10. Barner-Kowollik, C.; Vana, P.; Davis, T.P. The kinetics of free-radical polymerization. In Handbook of Radical Polymerization; Matyjaszewski, K., Davis, T.P., Eds.; John Wiley \& Sons, Inc.: Hoboken, NJ, USA, 2002; pp. 187-262, ISBN 978-0-471-22045-9.

11. Vana, P.; Barner-Kowollik, C.; Davis, T.P.; Matyjaszewski, K. Radical polymerization. In Encyclopedia of Polymer Science and Technology; Kroschwitz, J.I., Ed.; John Wiley \& Sons: New York, NY, USA, 2004; Volume 11, pp. 359-473.

12. Wojnarovits, L.; Takacs, E.; Biro, A. Propagation and Size-Dependent Chain Termination Rate Parameters in the Polymerisation of Acrylates in Aqueous Solution as Studied by Pulse Radiolysis. J. Macromol. Sci. A Pure Appl. Chem. 1995, 32, 443-454. [CrossRef]

13. Barner-Kowollik, C.; Buback, M.; Egorov, M.; Fukuda, T.; Goto, A.; Olaj, O.F.; Russell, G.T.; Vana, P.; Yamada, B.; Zetterlund, P.B. Critically Evaluated Termination Rate Coefficients for Free-Radical Polymerization: Experimental Methods. Prog. Polym. Sci. 2005, 30, 605-643. [CrossRef]

14. Russell, G.T.; Gilbert, R.G.; Napper, D.H. Chain-Length-Dependent Termination Rate Processes in Free-Radical Polymerizations. 1. Theory. Macromolecules 1992, 25, 2459-2469. [CrossRef]

15. Kadlubowski, S.; Grobelny, J.; Olejniczak, W.; Cichomski, M.; Ulanski, P. Pulses of Fast Electrons as a Tool to Synthesize Poly(Acrylic Acid) Nanogels. Intramolecular Cross-Linking of Linear Polymer Chains in Additive-Free Aqueous Solution. Macromolecules 2003, 36, 2484-2492. [CrossRef]

16. Ashfaq, A.; Clochard, M.-C.; Coqueret, X.; Dispenza, C.; Driscoll, M.S.; Ulański, P.; Al-Sheikhly, M. Polymerization Reactions and Modifications of Polymers by Ionizing Radiation. Polymers 2020, 12, 2877. [CrossRef]

17. Witcherle, O.; Lim, D. Hydrophylic Gels for Biological Use. Nature 1960, 185, 117-118.

18. Hoffman, A.S. Hydrogels for Biomedical Applications. Adv. Drug Deliv. Rev. 2002, 54, 3-12. [CrossRef]

19. Lee, K.Y.; Mooney, D.J. Hydrogels for Tissue Engineering. Chem. Rev. 2001, 101, 1869-1880. [CrossRef]

20. Rosiak, J.M.; Yoshii, F. Hydrogels and Their Medical Applications. Nucl. Instrum. Methods Phys. Res. Sect. B Beam Interact. Mater. At. 1999, 151, 56-64. [CrossRef]

21. Peppas, N.A. Hydrogels in Medicine and Pharmacy; CRC Press: Boca Raton, FL, USA, 1986.

22. Rosiak, J.M.; Olejniczak, J. Medical Applications of Radiation Formed Hydrogels. Radiat. Phys. Chem. 1993, 42, 903-906. [CrossRef]

23. Rosiak, J.M. Radiation Formation of Hydrogels for Drug Delivery. J. Control. Release 1994, 31, 9-19. [CrossRef]

24. Bromberg, L. Intelligent Hydrogels for the Oral Delivery of Chemotherapeutics. Expert Opin. Drug Deliv. 2005, 2, 1003-1013. [CrossRef]

25. Rosiak, J.M. Hydrogel dressings HDR. In Radiation Effects on Polymers; ACS Symposium Series 475; Clough, R.C., Shalaby, S.W., Eds.; American Chemical Society: Washington, DC, USA, 1991; pp. 271-299. [CrossRef]

26. Rosiak, J.; Rucinska-Rybus, A.; Pekala, W. Method of Manufacturing Hydrogel Dressings. U.S. Patent 4,871,490, 3 October 1989.

27. Ulanski, P.; Rosiak, J.M. Polymeric nano/microgels. In Encyclopedia of Nanoscience and Nanotechnology; Nalwa, H.S., Ed.; American Scientific Publishers: Stevenson Ranch, CA, USA, 2004; pp. 845-871.

28. Dispenza, C.; Spadaro, G.; Jonsson, M. Radiation Engineering of Multifunctional Nanogels. Top. Curr. Chem. 2016, $374,69$. [CrossRef] 
29. Adamo, G.; Grimaldi, N.; Sabatino, M.A.; Walo, M.; Dispenza, C.; Ghersi, G. E-Beam Crosslinked Nanogels Conjugated with Monoclonal Antibodies in Targeting Strategies. Biol. Chem. 2017, 398, 277-287. [CrossRef]

30. Rigogliuso, S.; Sabatino, M.A.; Adamo, G.; Grimaldi, N.; Dispenza, C.; Ghersi, G. Polymeric Nanogels: Nanocarriers for Drug Delivery Application. Chem. Eng. Trans. 2012, 27, 247-252. [CrossRef]

31. Dispenza, C.; Adamo, G.; Sabatino, M.A.; Grimaldi, N.; Bulone, D.; Bondì, M.L.; Rigogliuso, S.; Ghersi, G. OligonucleotidesDecorated-Poly(N-Vinyl Pyrrolidone) Nanogels for Gene Delivery. J. Appl. Polym. Sci. 2014, 131, 39774. [CrossRef]

32. Dispenza, C.; Sabatino, M.A.; Ajovalasit, A.; Ditta, L.A.; Ragusa, M.; Purrello, M.; Costa, V.; Conigliaro, A.; Alessandro, R. Nanogel-AntimiR-31 Conjugates Affect Colon Cancer Cells Behaviour. RSC Adv. 2017, 7, 52039-52047. [CrossRef]

33. Picone, P.; Sabatino, M.A.; Ditta, L.A.; Amato, A.; San Biagio, P.L.; Mulè, F.; Giacomazza, D.; Dispenza, C.; di Carlo, M. Nose-to-Brain Delivery of Insulin Enhanced by a Nanogel Carrier. J. Control. Release 2018, 270, 23-36. [CrossRef]

34. Picone, P.; Ditta, L.A.; Sabatino, M.A.; Militello, V.; San Biagio, P.L.; di Giacinto, M.L.; Cristaldi, L.; Nuzzo, D.; Dispenza, C.; Giacomazza, D.; et al. Ionizing Radiation-Engineered Nanogels as Insulin Nanocarriers for the Development of a New Strategy for the Treatment of Alzheimer's Disease. Biomaterials 2016, 80, 179-194. [CrossRef]

35. Kabanov, A.V.; Vinogradov, S.V. Nanogels as Pharmaceutical Carriers: Finite Networks of Infinite Capabilities. Angew. Chem. Int. Ed. 2009, 48, 5418-5429. [CrossRef]

36. Soni, K.S.; Desale, S.S.; Bronich, T.K. Nanogels: An Overview of Properties, Biomedical Applications and Obstacles to Clinical Translation. J. Control. Release 2016, 240, 109-126. [CrossRef]

37. Karg, M.; Pich, A.; Hellweg, T.; Hoare, T.; Lyon, L.A.; Crassous, J.J.; Suzuki, D.; Gumerov, R.A.; Schneider, S.; Potemkin, I.I.; et al. Nanogels and Microgels: From Model Colloids to Applications, Recent Developments, and Future Trends. Langmuir 2019, 35, 6231-6255. [CrossRef]

38. Matusiak, M.; Rurarz, B.P.; Kadłubowski, S.; Wolszczak, M.; Karczmarczyk, U.; Maurin, M.; Kolesińska, B.; Ulański, P. Synthesis and Properties of Targeted Radioisotope Carriers Based on Poly(Acrylic Acid) Nanogels. Pharmaceutics 2021, 13, 1240. [CrossRef]

39. Ulański, P.; Janik, I.; Rosiak, J.M. Radiation Formation of Polymeric Nanogels. Radiat. Phys. Chem. 1998, 52, 289-294. [CrossRef]

40. Kadlubowski, S.; Ulanski, P.; Rosiak, J.M. Synthesis of Tailored Nanogels by Means of Two-Stage Irradiation. Polymer 2012, 53, 1985-1991. [CrossRef]

41. Matusiak, M.; Kadlubowski, S.; Rosiak, J.M. Nanogels Synthesized by Radiation-Induced Intramolecular Crosslinking of Water-Soluble Polymers. Radiat. Phys. Chem. 2018, 169, 108099. [CrossRef]

42. Dispenza, C.; Grimaldi, N.; Sabatino, M.A.; Soroka, I.L.; Jonsson, M. Radiation-Engineered Functional Nanoparticles in Aqueous Systems. J. Nanosci. Nanotechnol. 2015, 15, 3445-3467. [CrossRef]

43. Sabatino, M.A.; Bulone, D.; Veres, M.; Spinella, A.; Spadaro, G.; Dispenza, C. Structure of E-Beam Sculptured Poly(NVinylpyrrolidone) Networks across Different Length-Scales, from Macro to Nano. Polymer 2013, 54, 54-64. [CrossRef]

44. An, J.-C.; Weaver, A.; Kim, B.; Barkatt, A.; Poster, D.; Vreeland, W.N.; Silverman, J.; Al-Sheikhly, M. Radiation-Induced Synthesis of Poly(Vinylpyrrolidone) Nanogel. Polymer 2011, 52, 5746-5755. [CrossRef]

45. Molyneux, P. Water-Soluble Synthetic Polymers: Properties and Applications; CRC Press: Boca Raton, FL, USA, 1987.

46. Bekturov, E.A.; Bakauova, Z.K. Synthetic Water-Soluble Polymers in Solution; Huethig \& Wepf: Basel, Switzerland, 1986.

47. Buchanan, K.J.; Hird, B.; Letcher, T.M. Crosslinked Poly(Sodium Acrylate) Hydrogels. Polym. Bull. 1986, 15, 325-332. [CrossRef]

48. Kaetsu, I.; Uchida, K.; Morita, Y.; Okubo, M. Synthesis of Electro-Responsive Hydrogels by Radiation Polymerization of Sodium Acrylate. Radiat. Phys. Chem. 1992, 40, 157-160. [CrossRef]

49. Jabbari, E.; Nozari, S. Swelling Behavior of Acrylic Acid Hydrogels Prepared by $\gamma$-Radiation Crosslinking of Polyacrylic Acid in Aqueous Solution. Eur. Polym. J. 2000, 36, 2685-2692. [CrossRef]

50. Ulanski, P.; Bothe, E.; Hildenbrand, K.; Rosiak, J.M.; von Sonntag, C. Hydroxyl-Radical-Induced Reactions of Poly(Acrylic Acid); a Pulse Radiolysis, EPR and Product Study. Part, I. Deoxygenated Aqueous Solutions. J. Chem. Society Perkin Trans. 2 1996, 1, 13-22. [CrossRef]

51. Ulanski, P.; Bothe, E.; Hildenbrand, K.; Rosiak, J.M.; von Sonntag, C. Hydroxyl-Radical-Induced Reactions of Poly(Acrylic Acid); a Pulse Radiolysis, EPR and Product Study. Part II. Oxygenated Aqueous Solutions. J. Chem. Society Perkin Trans. 2 1996, 1, 23-28. [CrossRef]

52. Ulański, P.; Bothe, E.; Hildenbrand, K.; von Sonntag, C.; Rosiak, J.M. The Influence of Repulsive Electrostatic Forces on the Lifetimes of Poly(Acrylic Acid) Radicals in Aqueous Solution. Nukleonika 1997, 42, 425-436.

53. Ulanski, P.; Rosiak, J.M. Pulse Radiolysis of Poly(Acrylic Acid) in Deoxygenated Aqueous Solution. J. Radioanal. Nucl. Chem. Lett. 1994, 186, 315-324. [CrossRef]

54. Ulanski, P.; Bothe, E.; Hildenbrand, K.; Rosiak, J.M.; von Sonntag, C. Radiolysis of Poly(Acrylic Acid) in Aqueous Solution. Radiat. Phys. Chem. 1995, 46, 909-912. [CrossRef]

55. Ulański, P.; Kadłubowski, S.; Rosiak, J.M. Synthesis of Poly(Acrylic Acid) Nanogels by Preparative Pulse Radiolysis. Radiat. Phys. Chem. 2002, 63, 533-537. [CrossRef]

56. Matusiak, M.; Kadlubowski, S.; Ulanski, P. Radiation-Induced Synthesis of Poly(Acrylic Acid) Nanogels. Radiat. Phys. Chem. 2018, 142, 125-129. [CrossRef]

57. Dispenza, C.; Sabatino, M.A.; Grimaldi, N.; Mangione, M.R.; Walo, M.; Murugan, E.; Jonsson, M. On the Origin of Functionalization in One-Pot Radiation Synthesis of Nanogels from Aqueous Polymer Solutions. RSC Adv. 2016, 6, $2582-2591$. [CrossRef] 
58. Adamo, G.; Grimaldi, N.; Campora, S.; Bulone, D.; Bondì, M.L.; Al-Sheikhly, M.; Sabatino, M.A.; Dispenza, C.; Ghersi, G. MultiFunctional Nanogels for Tumor Targeting and Redox-Sensitive Drug and SiRNA Delivery. Molecules 2016, 21, 1594. [CrossRef] [PubMed]

59. Grimaldi, N.; Sabatino, M.A.; Przybytniak, G.; Kaluska, I.; Bondì, M.L.; Bulone, D.; Alessi, S.; Spadaro, G.; Dispenza, C. High-Energy Radiation Processing, a Smart Approach to Obtain PVP-Graft-AA Nanogels. Radiat. Phys. Chem. 2014, 94, 76-79. [CrossRef]

60. Abd El-Rehim, H.A.; Hegazy, E.S.A.; Hamed, A.A.; Swilem, A.E. Controlling the Size and Swellability of Stimuli-Responsive Polyvinylpyrrolidone-Poly(Acrylic Acid) Nanogels Synthesized by Gamma Radiation-Induced Template Polymerization. Eur. Polym. J. 2013, 49, 601-612. [CrossRef]

61. Henke, A.; Ulanski, P.; Rosiak, J.M. Radiation cross-linked hydrogen-bonding interpolymer complexes. In Hydrogen-Bonded Interpolymer Complexes. Formation, Structure and Applications; Khutoryanskiy, V.V., Staikos, G., Eds.; World Scientific: Singapore, 2009; pp. 259-300, ISBN 978-981-270-785-7.

62. Ghaffarlou, M.; Sütekin, S.D.; Güven, O. Preparation of Nanogels by Radiation-Induced Cross-Linking of Interpolymer Complexes of Poly (Acrylic Acid) with Poly (Vinyl Pyrrolidone) in Aqueous Medium. Radiat. Phys. Chem. 2018, 142, 130-136. [CrossRef]

63. Rattanawongwiboon, T.; Ghaffarlou, M.; Sütekin, S.D.; Pasanphan, W.; Güven, O. Preparation of Multifunctional Poly(Acrylic Acid)-Poly(Ethylene Oxide) Nanogels from Their Interpolymer Complexes by Radiation-Induced Intramolecular Crosslinking. Colloid Polym. Sci. 2018, 296, 1599-1608. [CrossRef]

64. Buxton, G.V.; Greenstock, C.L.; Helman, W.P.; Ross, A.B. Critical Review of Rate Constants for Reactions of Hydrated Electrons, Hydrogen Atoms and Hydroxyl Radicals $\left(\mathrm{OH} / \mathrm{O}^{-}\right)$in Aqueous Solution. J. Phys. Chem. Ref. Data 1988, 17, 513-886. [CrossRef]

65. Von Sonntag, C.; Bothe, E.; Ulanski, P.; Deeble, D.J. Pulse Radiolysis in Model Studies toward Radiation Processing. Radiat. Phys. Chem. 1995, 46, 527-532. [CrossRef]

66. Lacík, I.; Stach, M.; Kasák, P.; Semak, V.; Uhelská, L.; Chovancová, A.; Reinhold, G.; Kilz, P.; Delaittre, G.; Charleux, B.; et al. SEC Analysis of Poly(Acrylic Acid) and Poly(Methacrylic Acid). Macromol. Chem. Phys. 2015, 216, 23-37. [CrossRef]

67. Karolczak, S.; Hodyr, K.; Łubis, R.; Kroh, J. Pulse Radiolysis System Based on ELU-6E LINAC. J. Radioanal. Nucl. Chem. 1986, 101, 177-188. [CrossRef]

68. Karolczak, S.; Hodyr, K.; Polowinski, M. Pulse Radiolysis System Based on ELU-6E LINAC. II. Development and Upgrading the System. Radiat. Phys. Chem. 1992, 39, 1-5. [CrossRef]

69. Schuler, R.H.; Patterson, L.K.; Janata, E. Yields for the Scavenging of OH Radicals in the Radiolysis of $\mathrm{N}_{2} \mathrm{O}-\mathrm{Saturated}$ Aqueous Solutions. J. Phys. Chem. 1980, 84, 2088-2089. [CrossRef]

70. Burchard, W. Static and Dynamic Light Scattering from Branched Polymers and Biopolymers. Adv. Polym. Sci. 1983, 48, 1-124. [CrossRef]

71. Serjeant, E.P.; Dempsey, B. Ionisation Constants of Organic Acids in Aqueous Solution; IUPAC Chemical Data Series No. 23; Pergamon Press: Oxford, UK, 1979.

72. Katchalsky, A.; Gillis, J. Theory of the Potentiometric Titration of Polymeric Acids. Recl. Des Trav. Chim. Des Pays Bas 1949, 68, 879-897. [CrossRef]

73. Oosawa, F. Polyelectrolytes; Marcel Dekker: New York, NY, USA, 1971.

74. Morawetz, H. Macromolecules in Solution; Interscience Publishers: New York, NY, USA, 1965.

75. Charlesby, A. Atomic Radiation and Polymers; Pergamon Press: Oxford, UK, 1960.

76. Coqueret, X. Obtaining High-Performance Polymeric materials by Radiation. In Radiation Chemistry: From Basics to Applications in Material and Life Sciences; Spotheim-Maurizot, M., Mostafavi, M., Douki, T., Belloni, J., Eds.; EDP Sciences: Les Ulis, France, 2008; pp. 131-150.

77. Coqueret, X.; Sabharwal, S.; Khairul Zaman, H.M.D.; Czechowska-Biskup, R.; Wach, R.A.; Rosiak, J.M.; Ulanski, P. Introduction to the radiation chemistry of polymers. In The Radiation Chemistry of Polysaccharides; Al-Assaf, S., Coqueret, X., Khairul Zaman, M.H.D., Sen, M., Ulanski, P., Eds.; IAEA: Vienna, Austria, 2016; pp. 25-75.

78. Buxton, G.V. Radiation chemistry of the liquid state. Water and homogeneous aqueous solutions. In Radiation Chemistry: Principles and Applications; Farhataziz, Rodgers, M.A.J., Eds.; Verlag Chemie: Weinheim, Germany, 1987; pp. 321-349.

79. Von Sonntag, C. The Chemical Basis of Radiation Biology; Taylor and Francis: London, UK, 1987.

80. Buxton, G.V. An overview of the radiation chemistry of liquids. In Radiation Chemistry: From Basics to Applications in Material and Life Sciences; Spotheim-Maurizot, M., Mostafavi, M., Douki, T., Belloni, J., Eds.; EDP Sciences: Les Ulis, France, 2008 ; pp. 3-16.

81. Jonah, C.D.; Miller, J.R.; Matheson, M.S. The Reaction of Hydrated Electron + Oxonium. Concentration Effects of Acid or Salts. J. Phys. Chem. 1977, 81, 931-934. [CrossRef]

82. Janata, E.; Schuler, R.H. Rate Constant for Scavenging $\mathrm{e}_{\mathrm{aq}}^{-}$in $\mathrm{N}_{2} \mathrm{O}-$ Saturated Solutions. J. Phys. Chem. 1982, 86, $2078-2084$. [CrossRef]

83. Bartoszek, N.; Ulański, P.; Rosiak, J.M. Reaction of a Low-Molecular-Weight Free Radical with a Flexible Polymer Chain: Kinetic Studies on the $\mathrm{OH}+\operatorname{Poly}(\mathrm{N}-$ Vinylpyrrolidone) Model. Int. J. Chem. Kinet. 2011, 43, 474-481. [CrossRef]

84. Ulanski, P.; Bothe, E.; Rosiak, J.M.; von Sonntag, C. Radiolysis of the Poly(Acrylic Acid) Model 2,4-Dimethylglutaric Acid: A Pulse Radiolysis and Product Study. J. Chem. Society. Perkin Trans. 2 1996, 1, 5-12. [CrossRef]

85. Görlich, W.; Schnabel, W. Untersuchungen über der Einfluss der Ladungsdichte auf die Gegenseitige Desaktivierung von Polyion-Makroradikalen. Die Makromol. Chem. 1973, 164, 225-235. [CrossRef] 
86. Ulanski, P.; Bothe, E.; Hildenbrand, K.; von Sonntag, C. Free-Radical-Induced Chain Breakage and Depolymerization of Poly(Methacrylic Acid): Equilibrium Polymerization in Aqueous Solution at Room Temperature. Chem. A Eur. J. 2000, 6, 3922-3934. [CrossRef]

87. Behar, D.; Rabani, J. Pulse Radiolysis of Poly(Styrenesulfonate) in Aqueous Solutions. J. Phys. Chem. 1988, 92, 5288-5292. [CrossRef]

88. Ulanski, P.; Bothe, E.; Rosiak, J.M.; von Sonntag, C. OH-Radical-Induced Crosslinking and Strand Breakage of Poly(Vinyl Alcohol) in Aqueous Solution in the Absence and Presence of Oxygen. A Pulse Radiolysis and Product Study. Makromol. Chem. 1994, 195, 1443-1461. [CrossRef]

89. Ulanski, P.; Rosiak, J.M.; Zainuddin, A. Pulse Radiolysis of Poly(Ethylene Oxide) in Aqueous Solution. II. Decay of Macroradicals. Radiat. Phys. Chem. 1995, 46, 917-920. [CrossRef]

90. Janik, I.; Ulanski, P.; Hildenbrand, K.; Rosiak, J.M.; von Sonntag, C. Hydroxyl-Radical-Induced Reactions of Poly(Vinyl Methyl Ether): A Pulse Radiolysis, EPR and Product Study in Deoxygenated and Oxygenated Aqueous Solutions. J. Chem. Society. Perkin Trans. 2 2000, 2041-2048. [CrossRef]

91. Sabharwal, S.; Mohan, H.; Bhardwaj, Y.K.; Majali, A.B. Structure-Reactivity Studies on the Crosslinking of Poly(Vinyl Methyl Ether) in Aqueous Solutions: A Pulse Radiolysis Study. J. Chem. Soc. Faraday Trans. 1996, 92, 4401-4406. [CrossRef]

92. Jeszka, J.K.; Kadlubowski, S.; Ulanski, P. Monte Carlo Simulations of Nanogels Formation by Intramolecular Recombination of Radicals on Polymer Chain. Dispersive Kinetics Controlled by Chain Dynamics. Macromolecules 2006, 39, 857-870. [CrossRef]

93. Ulański, P.; Kadłubowski, S.; Jeszka, J.K. Nanogel Formation by Intrachain Radiation-Induced Cross-Linking. Simulation and Experiment. Mater. Sci. Pol. 2006, 24, 467-476.

94. Dahlgren, B.; Dispenza, C.; Jonsson, M. Numerical Simulation of the Kinetics of Radical Decay in Single-Pulse High-Energy Electron-Irradiated Polymer Aqueous Solutions. J. Phys. Chem. A 2019, 123, 5043-5050. [CrossRef] [PubMed]

95. Dahlgren, B.; Sabatino, M.A.; Dispenza, C.; Jonsson, M. Numerical Simulations of Nanogel Synthesis Using Pulsed Electron Beam. Macromol. Theory Simul. 2020, 29, 1900046. [CrossRef]

96. Plonka, A. Developments in Dispersive Kinetics. Prog. React. Kinet. 1991, 16, 157-333.

97. Plonka, A. Dispersive Kinetics; Kluwer Academic Publishers: Dordrecht, The Netherlands, 2001; ISBN 0-7923-7128-3.

98. Neta, P.; Simic, M.; Hayon, E. Pulse Radiolysis of Aliphatic Acids in Aqueous Solutions. I. Simple Monocarboxylic Acids. J. Phys. Chem. 1969, 73, 4207-4213. [CrossRef]

99. Smoluchowski, M. Versuch Einer Mathematischen Theorie der Koagulationskinetik Kolloider Lösungen. Z. Phys. Chem. 1917, 92, 129-168. [CrossRef]

100. Russell, G.T.; Napper, D.H.; Gilbert, R.G. Termination in Free-Radical Polymerizing Systems at High Conversion. Macromolecules 1988, 21, 2133-2140. [CrossRef]

101. Gillespie, D.T. A General Method for Numerically Simulating the Stochastic Time Evolution of Coupled Chemical Reactions. J. Comput. Phys. 1976, 22, 403-434. [CrossRef]

102. Hinsberg, W.; Houle, F. Kinetiscope: A Stochastic Kinetics Simulator. Available online: http://hinsberg.net/kinetiscope/ (accessed on 26 October 2021). 